\title{
Sandor Ferenczi: na história e na atualidade da psicanálise
}

\section{Algumas contribuições para o tema da formação e técnica psicanalítica}

\section{Tadeu Oliveira de Aguiar}

Psicanalista, membro do Grupo Brasileiro de Pesquisas Sándor Ferenczi e do International Sándor Ferenczi Network, membro efetivo da Práxis Psicanalítica, membro associado do Instituto Brasileiro de Psicanálise, Ciências Humanas e Sócias

(IBRAPCHS), graduando em psicologia pela Universidade Estácio de Sá e em Tecnologia em Gerontologia pelo Centro Universitário Uninter.

Instituição atual: Práxis Psicanalítica

\section{E-mail.psicanalista9@gmail.com}

\section{Resumo}

Este artigo de cunho teórico/bibliográfico tem como objetivo geral, apresentar de forma introdutória a vida pessoal e profissional desse psicanalista eminentemente clínico e ainda, pouco conhecido. Como objetivo específico, nesse artigo, iremos nos debruçar na contribuição de Ferenczi, para a formação dos psicanalistas e principalmente sobre a análise do analista. A metodologia utilizada nesse artigo é a revisão dos principais textos no qual Ferenczi trata da técnica e formação psicanalítica. Entendemos esse trabalho de suma importância e relevância, para a contribuição do processo de formação e para técnica psicanalítica em nosso país. Nessa pesquisa temos a hipótese, de que, a experiência analítica, é, indissociável do processo de formação e a dá importância de Ferenczi, para a técnica e clínica psicanalítica no contemporâneo.

Palavras-chave: Ferenczi. Formação do psicanalista. Análise pessoal. 


\section{Introdução}

Sandor Ferenczi, foi um psicanalista que muito contribuiu para a teoria da técnica e prática clínica. Sua obra tem sido objeto de pesquisa nos últimos anos, principalmente, com a catástrofe da covid-19, na qual levou os psicanalistas a mudarem e repensarem suas formas de praticar a clínica, por conta da obrigatoriedade do isolamento social. Um texto, que tem, sido muito debatido, é, o da Elasticidade da Técnica (1928), partindo desse texto, para se pensar como o analista de frente as condições de horror da pandemia, pode utilizar de uma técnica psicanalítica de uma forma mais acessível aos traumas vividos pela sociedade e como o analista precisa se flexibilizar diante dos contratempos do atendimento online.

Esse artigo é baseado na apresentação que foi realizada no 7, julho 2021 pelo canal do Youtube: Fórum de Discussões - Práxis Psicanalítica, no qual, foi realizado a comemoração dos 148 anos de Sandor Ferenczi, tendo como apresentação o tema: Sandor Ferenczi na história e na atualidade da psicanálise e algumas de suas contribuições acerca da formação do psicanalista. O objetivo geral desse artigo, é, apresentar de forma introdutória, a vida pessoal e psicanalítica de Sandor Ferenczi. Tendo como objetivo especifico as suas contribuições para a formação do psicanalista.

A metodologia da presente pesquisa, é a revisão dos textos: A técnica psicanalítica (1919), O problema do fim de análise (1927), Elasticidade da técnica (1927-1928) e o primeiro texto intitulado que se detém especificamente ao "Processo da formação psicanalítica" (1928). Para apresentar uma breve bibliografia de Ferenczi, iremos utilizar o texto de Introdução escrito pelo psicanalista Michael Balint da "Obras completas psicanálise I, livro Por que Ferenczi? e tendo como base central a apresentação em homenagem aos 148 anos de Sandor Ferenczi, apresentado pelo psicanalista Tadeu de Aguiar (Fórum de Discussões - Práxis Psicanalítica).

Na primeira sessão, apresentaremos de forma introdutória a vida do psicanalista Ferenczi, seu encontro com a psicanálise e suas contribuições e obras psicanalíticas.

Na segunda sessão, analisaremos sobre formação do psicanalista, a partir, do texto de Ferenczi, inaugural no movimento psicanalítico, intitulado como "O processo de formação psicanalítica (1928). 
Na terceira sessão, iremos verificar a importância da análise do analista em formação e sua importância, em geral, para o fazer do psicanalista.

Na quarta e última sessão, em considerações finais, com a hipótese de que, a partir de Ferenczi, a formação do psicanalista se encontra no campo da experiência, formulando, então, a frase do autor de que: "A psicanálise não se aprende, se experimenta" partindo dessa frase, entendemos que, a formação em psicanálise é inacabável e experiencial. Sendo assim, não se torna analista e sim, se sustenta como analista, a partir, do tripé freudiano.

\section{Quem foi Sándor Ferenczi?}

Sandor Ferenczi, nascido em 7 de julho 1873 no interior da Hungria, foi o quinto filho dos homens e oitavo de um total de doze filhos do casal Baruch. Segundo KUPERMANN (2019), o sobrenome de origem judaica, foi alterado posteriormente por "Ferenczi". Ferenczi, perdeu seu pai ainda bem jovem, aos 15 anos, perda que foi muito sentida pelo jovem. Aos 17 anos, inicia seus estudos em medicina em Viena, nessa época, sua mãe já era viúva e levava a frente a livraria, na qual seu marido falecido era proprietário. Sobre seu percurso escolar, Ferenczi, relatou para Balint, que não foi tão aplicado, como era no período escolar. Cito BALINT (2011), “diferente dos anos escolar, na universidade, não foi um bom aluno, "preferiu a boa vida" (BALINT, 2011). BALINT (2011). na introdução das obras completas, volume I, comenta que Ferenczi, sofria de uma forte carência fraterna e que tinha uma personalidade, um tanto calorosa. Esse estilo sensível de Ferenczi, irá marcar o cuidado e preocupação com clínica. Ferenczi, foi um analista que se preocupou com os mais vulneráveis de sua época, como crianças, as mulheres e os homossexuais.

Um fator interessante é, que, Ferenczi, estudou na mesma universidade na qual Freud, se formou, no ano em que Ferenczi nascia. Mesmo estudando em Viena, nunca tinha ouvido falar de Freud. Em 1894 Ferenczi, se forma em medicina e retorna a Budapest (KUPERMANN, 2919, pág. 171). Ferenczi, passa a trabalhar como médico assistente no Hospital São Roque, em Budapest, na qual irá viver por quase toda a sua vida e onde irá atuar com a prática psicanalítica (KUPERMANN, 2919, pág. 171). Em 1907 Ferenczi, conhece Karl Jung por intermédio de Fullop Stein, e começa a praticar as teses de associação de palavras de Jung. Ferenczi é apresentado a Freud, por Jung em 1908. 
De acordo KUPERMANN (2019), Freud e Ferenczi, se conhecem em fevereiro de 1908 e imediatamente após esse encontro Ferenczi, começa a divulgar a psicanálise em Budapest, proferindo palestras na Sociedade Médica e em encontros culturais na cidade.

No mesmo ano, Ferenczi, apresenta um trabalho no encontro Internacional de Psicanálise, intitulado de "Psicanálise e Pedagogia". De acordo BALINT (2011), Ferenczi, exerceu a clínica geral, até 1910, e depois, abandona, para se dedicar inteiramente, ao ofício da psicanálise. E justamente em 1910, Ferenczi, participa do $2^{\circ}$ Congresso Internacional de Psicanálise, profere a conferência "Sobre a história do movimento psicanalítico" Ferenczi, propõe a criação de uma associação internacional de psicanálise (KUPERMANN, 2019pág. 172), e justamente, algum tempo depois, foi criada a sociedade que veio ficar conhecida como IPA.

Um outro fator interessante, é que, mesmo antes de Ferenczi, conhecer Freud, ele já tinha contato com a obra freudiana. Fato este que, existe uma divergência de informação que, de acordo Balint (2011), Ferenczi, teve sua primeira oportunidade de ler a obra freudiana, a Interpretação dos Sonhos, no qual, foi convidado, a redigir uma nota sobre o texto, à qual se recusou após foliar, algumas páginas da obra, e achou que não valeria a pena. E segundo KUPERMANN (2019), Ferenczi, teve contato com um texto de Freud "Sobre o mecanismo psíquico dos fenômenos histéricos: comunicação preliminar" (1893), Ferenczi, teve esse texto em mãos, no mesmo ano da publicação de Freud com Breuer. Muito provável a informação de KUPERMANN, ser a mais precisa, pois, desde o início, Ferenczi, se interessa, por estudos técnicos e métodos voltados aos processos mentais. Prova do interesse de Ferenczi, pelos processos mentais é, que, segundo a Balint, Ferenczi, ficou sabendo, que em Zurique, tinha um método que permitia medir o funcionamento mental das pessoas. Cito Balint:" Era algo suficiente preciso para seduzi-lo; comprou um cronômetro e, a partir desse instante, ninguém escapou ao seu zelo. Quem ficasse ao seu alcance nos cafés de Budapest, escritor, poeta, pintor, zelador dos banheiros, ou garçons, era irremediavelmente, submetido à "prova de associação" (BALINT, 2011). Portanto, é muito possível que Ferenczi, tenha tido contato com a obra de Freud, mas, talvez, não tenha causado grande interesse, até aquele momento. Que mais tarde foi inevitável, pois, sempre interessado pelas questões mentais, foi levado a ler as obras psicanalíticas, disponível na época, sendo que aos 34 anos, no ano de 1908, escreveu pela primeira vez a Freud, pedindo que ele, concedesse uma entrevista. Freud, 
ficou impressionado com sua capacidade e conhecimento dos materiais psicanalíticos, o convidou para o congresso de psicanálise, em Salzburgo, em abril de 1908.

Em 1909, quando Freud, foi aos Estados Unidos, levando Ferenczi, sendo o início de uma grande amizade tranquila, durante muitos anos, que assim permaneceu até à Primeira Guerra Mundial (BALINT,2011).

Em 1913, Ferenczi, funda a Sociedade Psicanalítica de Budapest, recebe Ernest Jones, como analisando, a pedido de Freud e escreve um grande outro texto: O desenvolvimento do sentido de realidade e seus estágios (KUPPERMAN, 2019, pág. 173). Em 1914, que Ferenczi, começa sua primeira análise com Freud e recebe Melaine Klein como paciente, sendo Klein, muito influenciada mais tarde pela obra de Ferencziana. No quinto Congresso Internacional de Psicanálise, no qual Freud, apresenta o texto "Caminhos da terapia psicanalítica" (1918), segundo KUPPERMAN (2019), Freud, enaltece as pesquisas e contribuições clínicas de Ferenczi.

Desde o início do contato de Ferenczi, com a psicanálise, ele, destacou pelo seu interesse na técnica e clínica psicanalítica. No ano de sua viagem aos Estados Unidos, Ferenczi escreve um texto eminentemente clínico, Transferência e Introjeção (1909), um texto fundamental para a técnica e clínica. De acordo, KUPERMANN (2019), é o primeiro e grande ensaio de Ferenczi.

Vale destacar, que o conceito de introjeção, foi utilizado depois por vários psicanalistas, principalmente, Melanie Klein, que foi sua analisanda por duas vezes. Segundo o próprio Freud, no obituário de Ferenczi, escreve: que já nos auge dos cinquenta anos, Ferenczi: "já havia publicado a maior parte de seus trabalhos, que tornaram todos os analistas seus discípulos" e continua Freud: “É impossível imaginar que a história de nossa ciência algum dia venha a esquecê-lo" (FREUD, 1933, pág. 278-279). Infelizmente, foi exatamente, o que ocorreu, um esquecimento induzido por Ernest e pelo próprio Freud.

De acordo AGUIAR (2021), Ferenczi, teve suas contribuições silenciadas por quase cinquenta anos após a sua morte. Ocultando suas obras aos novos psicanalistas em formação, alegando Ernest Johns, que, Ferenczi, estava louco, colocando em dúvida sua sanidade mental. Só na década de oitenta, especificamente no Brasil, que as contribuições de Ferenczi, a partir, da primeira pesquisa publicada por Tereza Pinheiro, que é a pioneira nos estudos de Ferenczi, no Brasil. Em seguida foi sendo disseminado o pensamento, passando a ser de acesso dos psicanalistas, a publicação do seu Diário Clínico (1933), que foi guardado anos pelo psicanalista Michael Balint, que o preservou para o momento em 
que a comunidade psicanalítica estivesse mais madura, para lidar com questões estritamente delicadas para uma ampliação e alteração da teoria e técnica psicanalítica. Freud, ao escrever no obituário em homenagem a Ferenczi, escreve que ele tinha se lentamente do meio psicanalítico (FREUD, 1933, pág. 279), segundo AGUIAR (2021), o psicanalista argentino, Juan Davi Nasio, relata que Freud, tinha toda razão, pois Ferenczi, estava no século XXI, pensando o fazer clínico, contribuindo para a psicanálise no contemporâneo.

Sandor Ferenczi, muito contribuiu para a psicanálise na história e na atualidade, inclusive, tratando um tema no qual Freud, não tinha tratado que era o fim de análise. Ferenczi escreve o texto: O problema do fim de análise (1927) e Freud, a exatamente dez anos após, escreve para tratar a questão do fim de análise no texto: Análise finita e análise infinita (1937). O Processo da formação psicanalítica (1928), foi o primeiro texto psicanalítico em que se tratava a questão da formação. Apesar de Freud, já ter escritos e feitos várias recomendações sobre a formação do analista, foi Ferenczi, que dedica um texto somente para esse tema. Dois outros conceitos no qual Ferenczi contribuiu, foi para a técnica psicanalítica, foi a necessidade de que, o analista precisa ter empatia, "sentircom" com os pacientes e "tato psicológico", ao comunicar as interpretações aos pacientes (FERENCZI, 1928)

Ferenczi, sempre voltado para a técnica e clínica, irá se debruçar e, muito contribuir para o tema da formação do analista, principalmente com a análise pessoal do analista sendo a mais importante base do tripé da formação, colocando-a como a segunda regra fundamental da psicanálise, após a associação livre do analisando (FERENCZI, 1928-2011) p. 31). E será o tema da análise do analista e o processo da formação em psicanálise, dentre tantas outras contribuições de Ferenczi, que iremos tratar a seguir.

\section{O processo da formação psicanalítica: a experiencia analítica e a formação do psicanalista}

Sándor Ferenczi, tem um texto intitulado: O processo da formação psicanalítica (1928), extraído de um ciclo de conferências na qual ele deu em Madri (FERENCZI,2011, pág. 237), nesse texto ele trata exclusivamente sobre a formação do analista. Freud, já tinha escrito vários textos no qual mencionava do que se tratava a formação do analista, Análise Leiga (1926), Recomendações ao médico para o tratamento psicanalítico (1912), 
Sobre o ensino da psicanálise nas universidades (1918) e outros textos técnicos. Mas sendo Ferenczi, que escreveu um texto que se tratava especificamente do tema da formação do analista.

O processo da formação psicanalítica (1928), é um texto no qual Ferenczi, vai tratar do percurso da formação analítica baseando-se no tripé que já tinha sido proposto por Freud, análise pessoal, supervisão e estudo teórico. Partindo de dois momentos importantes da formação, Ferenczi, destaca, nesse texto, a análise como a primeira base do tripé fundamental para que ocorra um percurso de formação, ou seja, colocando a análise pessoal anterior ao estudo teórico como veremos mais à frente.

Interessado com a técnica psicanalítica e o efeito clínico dos pacientes, Ferenczi faz a abertura do texto, com uma pergunta: como se estuda psicanálise? E quem pode aspirar o "título de psicanalista?

Ferenczi, descreve que diferente de outras ciências e campos de outros saberes mais objetivos, no qual é aprendido nas universidades e a partir de exames rigorosos (provas), e os aspirantes passando nesses exames, confere se o direito de praticar e exercer a profissão. Sendo diferente o percurso de formação do psicanalista, na qual para se tornar psicanalista, é imprescindível que o aspirante tenha um mínimo de experiência, não só uma experiência clínica com pacientes, mas anterior a esta, ou seja, uma experiência analítica, que é indispensável para quem deseja praticar a psicanálise. Cito Ferenczi:

(...) a experiencia psicanalítica mostra que, praticar o ofício de psicanalista, não basta estabelecer uma relação lógica entre conhecimentos e os dados experimentais; é indispensável, além disso, efetuar um estudo profundo da nossa própria personalidade e uma observação rigorosa das nossas moções psíquicas e afetivas (FERENCZI, 1928-2011, pág. 238)

Ou seja, se tornando objeto da própria análise, com seus próprios complexos, questões pessoais, ou seja, uma experiência com seu próprio inconsciente. $\mathrm{O}$ inconsciente como proposta base da psicanálise, é, o que analista precisa encontrar em sua experiência de análise. Não são suficientes o domínio teórico psicanalítico e o conhecimento da hipótese do inconsciente, é, preciso saber de seu próprio inconsciente. De acordo FERENCZI (1928-2011), para esse saber se converta em convicção é necessário passar uma experiência pessoal. É a partir das suas próprias contradições, complexos, chistes, atos falhos, sonhos e sintoma na experiência analítica, é, que o analista poderá se colocar nesse lugar de analista após ter atravessado um percurso de análise. Ainda nesse texto, 
Ferenczi, destaca que não é possível uma autoanálise, que é, necessário que um outro analista assista esse processo, dentro da experiencia da transferência, com tato e firmeza (FERENCZI, 1928-2011, pág. 240). Como podemos constatar a partir de Ferenczi, o início da formação psicanalítica, começa-se em nossa própria análise, ou seja, ao percorrer um tempo de análise, em seguida estudos teóricos, Ferenczi, coloca a supervisão em um segundo momento, posterior a experiencia analítica.

Cito Ferenczi:

(...) o segundo tempo é representado pela chamada análise "sob controle". São confiadas ao aluno algumas análises; ele trabalha sozinho, mas vai periodicamente prestar conta de seu trabalho ao seu supervisor, que poderá chamar-lhe a atenção para eventuais erros técnicos, aconselhá-lo quanto à maneira de conduzir o tratamento (FERENCZI, 1928-2011, pág. 241).

É um texto riquíssimo e, muito poríamos desdobrar boas considerações, como as instituições que ofereciam a formação psicanalítica e a questão da formação universitária. Mas iremos nos limitar nesse texto, a questão da experiência analítica como condição fundamental para que haja uma formação.

\section{Análise pessoal do psicanalista}

Aprofundando mais, a importância da análise do analista em formação, cito Ferenczi: "sendo o essencial da formação analítica, sua condição sine qua non; a formação teórica e prática só ode vir em seguida” (FERENCZI, 1928, pág. 238).

No Congresso Internacional de Psicanálise em Insbruck, no dia 3 de setembro de 1927, Ferenczi, apresenta um texto intitulado como: O problema do fim de análise, no qual ele destaca mais uma vez a importância da análise do analista e, indo além, colocando como condição fundamental que, o analista leve sua análise até o "fim". Algumas questões nas quais Lacan, trabalhou em seu percurso, como: a formação do analista e o fim de análise, muito possível que advém do Ferenczi, mesmo sem citá-lo. O que Ferenczi, propõe que o analista leve até o fim sua análise, ou melhor, esgote seus complexos, podemos fazermos um ponto com o que Lacan, irá relatar como "travessia da fantasia".

Podemos dizer que, para o analista, sustentar esse lugar de analista, precisa atravessar seus "complexos", suas fantasias, até o fim. Ao descrever mais uma vez a importância da análise do analista em formação, Ferenczi, descreve sua preocupação com as análises didáticas proposta pela IPA, que tinha como orientação que o candidato a 
psicanalista, passasse aproximadamente um ano de análise didata, para Ferenczi, não sendo o suficiente, pois era necessário que o mesmo levasse sua análise até o fim, cito Ferenczi: "Faço esta observação porque, com frequência, considera-se o suficiente que o candidato a psicanalista trave conhecimento, durante um ano, por exemplo, com os principais mecanismos: uma análise suspostamente didática" e continua Ferenczi, “assinalei amiúde, no passado que não via nenhuma diferença de princípio entre análise terapêutica e análise didática (FERENCZI, 1927-2011,pág. 24).

Ferenczi, relata que, o analista, de quem depende o destino de tantos seres, deve conhecer suas fraquezas e complexos mais profundos de sua personalidade, o que segundo ele, é, impossível sem uma análise inteiramente terminada (FERENCZI, pág. 24). Sabemos, que o tema do fim de análise, é um tema um tanto debatido no campo psicanalítico. Talvez, não seja possível esgotar todas as questões inconsciente, muito provável que não. Mas a partir de Ferenczi, a quase um século atrás, podemos constatar a importância de um duro e longo percurso de análise pessoal, para que possa a pessoa se colocar nessa empreitada de praticar a psicanálise.

O tema da análise pessoal como (terapêutica) e não de "educação", hoje, mais do que nunca talvez, seja relevante ser novamente discutida e colocada em pauta. Em meio tantas propostas pela internet de cursos de "formações" duvidosas e extremamente rápidas, desmiuçar e transmitir a análise como primeiro passo para haja uma formação, é, de extrema importância. E, é a partir de Ferenczi, que estamos destacando algumas de suas contribuições sobre o tema proposto e que visivelmente, muito possível, Lacan, ter bebido muito das fontes de Ferenczi, para se debruçar sobre o tema da formação, colocando em um nível, além de conhecimento e saber objetivo e sim, de um saber daquilo que se é base da psicanálise, o inconsciente.

Para finalizarmos os destaques desse texto de Ferenczi (1927), ele relata que um dos possíveis sinais do fim de uma análise, seria quando o analisante, está convencido de que a análise, para ele é uma fantasia, um novo meio de satisfação e que não lhe fornece nada a realidade. Ou seja, aquilo que entendemos como fim de análise, em que o analista caí, não sendo mais um objeto fantasiado para o analisante e como efeito desse "cair" do analista, o analisante "passa" de posição, de analisante para analista. Ou seja, ser psicanalista, é uma fantasia de um fim de análise, ou melhor, um resto que se sobra da fantasia em um fim de análise. 


\section{A técnica psicanalítica em Ferenczi: psicanálise não se aprende se experimenta}

Sandor Ferenczi, foi um psicanalista, eminentemente clínico, sempre voltado para as questões técnicas e clínicas. De acordo com COSTA, AGUIAR (2021), "Ferenczi, sempre as voltas de testar a técnica psicanalítica para os "tipos" pacientes difíceis, ou seja, não neuróticos, faz grandes ampliações para a clínica e técnica psicanalítica". Em dificuldades técnicas em análise de histeria (1919), ao encontrar dificuldades com a técnica psicanalítica, Ferenczi, propõe mudanças na técnica que irá dar início aos experimentos da técnica ativa. A técnica ativa, propõe uma presença mais ativa do analista. $\mathrm{O}$ analista, provocaria no relacionamento transferencial afetos tantos amorosos, como hostis no paciente, com o intuito de interpretar e atuar levando o paciente a tomar consciência. Sugestionava, leva o paciente fóbico a enfrentar seu medo entre outros atos no qual fazia se necessário para que a análise andasse mais rápido ou não estagnasse. Anos depois Ferenczi, vai abandonando a técnica por perceber que não era tão eficaz em todos os casos e principalmente abria margens para riscos. Vale lembrar, que Ferenczi, nunca abandonou a regra fundamental da psicanálise como técnica principal da psicanálise, mas se viu diante de casos difíceis, tanto de neuroses como de não neuroses que, se viu impelido a fazer ampliações. Ora, Ferenczi, foi um experimentador e inovador, que no contemporâneo quanto de nós analistas, não nos encontramos com casos que ficam estagnados ou casos no qual a técnica psicanalítica não dá conta? Ferenczi, fez várias recomendações e contraindicações da técnica ativa como no texto Contraindicações da técnica ativa FERENCZI, 1926). A proposta aqui, não é escrever sobre as experiencias técnicas de Ferenczi, que já bem conhecida no meio acadêmico e psicanalítico. A proposta é de destacar a preocupação e a assertividade de Ferenczi, em amplia a técnica tornando a psicanálise apta para casos difíceis no contemporâneo, com isso irá propor outras mudanças técnicas, mudanças que são de extrema importância para a clínica hoje.

Essas mudanças podemos destacar, no texto da Elasticidade da técnica, FERENCZI (1927-1928/2011), novamente preocupado com técnica psicanalítica, propõe que o analista precisava ter uma espécie de tato psicológico, ao comunicar as interpretações aos analisandos. Ou seja, da técnica ativa onde o analista provocava afetos na transferência, Ferenczi, vai para o tato psicológico e elasticidade da técnica.

De acordo FERENCZI, é a faculdade do analista de sentir com, ou seja, uma convocação para que os analistas atuassem com empatia. Sem dúvidas, não podemos confundir empatia, com se misturar com as questões do analisando, ou estar na clínica no lugar do 
"Eu" da pessoa do analista, mas talvez, um intermediário, direcionando o tratamento analítico, com empatia, mas como baliza a regra fundamento "associação livre". Podemos perceber hoje, no meio psicanalítico, um extremismo, de um lado com todo vigor, o analista "interpretador" que, lança sua interpretação e que o analisando banque seu desejo e angústia. Por um outro lado, um analista, excessivamente empático, sensível ao extremo e que mais parece que o analista é arrastado pelas ocorrências da clínica e muita das vezes não sustentam não é a angústia do analisando e sim as suas próprias. Sendo assim, é de extrema relevância que os analistas do contemporâneo esteja, ciente da subjetividade de sua época, na qual convoca sim a presença de um analista empático, que senti com e com tato psicológico, mas que não renuncie à regra fundamental da associação livre e do inconsciente onde habita o desejo reprimido.

Como tese principal as contribuições de Ferenczi, para a técnica. Queremos aqui, destacar que da técnica ativa a elasticidade da técnica, existe muito o que se pesquisar sobre esses pontuais contribuições de Ferenczi, que ambas podem ser fundamentais na clínica, desde que haja, um limite, ou melhor, uma ética, não a da moral ou da filosofia, mas a ética da psicanálise. Na qual podemos criar um diálogo com a ética do desejo em Lacan, imprescindível para a práxis psicanalítica e a ética do cuidado em Ferenczi. Talvez, um denso diálogo entre ambas propostas, podem levar a clínica psicanalítica a novos e frutíferos rumos para nossa época.

Por fim, podemos perceber que o quanto Ferenczi, ousou em sua época, fazer ampliações técnicas. Porém, técnicas essas, nas quais, exigem do analista, uma experiência analítica. Não somente a de conduzir uma análise, mas, uma experiencia própria com seu inconsciente. Partindo da tese principal dessa sessão que, "psicanálise não se aprende, se experimentar, só sendo possível, cito Ferenczi, a partir de Pinheiro (2016) "É preciso ter tido uma vivência afetiva, ter experimentado na própria carne, para atingir um grau de certeza que mereça o nome de "convicção" (PINHEIRO, 2016, p. 46). 


\section{Considerações finais}

Como foi descrito no resumo, este artigo é resultado da palestra em homenagem aos 148 anos de Sandor Ferenczi, e, foi, uma enorme satisfação falar de sua vida e suas contribuições para a formação e técnica psicanalítica. Mas, levando em conta que uma palestra passa pelo crivo do tempo, tentei aqui, de uma forma um pouco mais aprofundada, descrever, principalmente suas contribuições para formação do psicanalista e para a clínica. O intuito desse trabalho foi, de disseminar um pouco mais, as ideias de Ferenczi e principalmente destacar suas contribuições. Levando em conta que, hoje, a leitura da obra ferencziana, é, necessária para formação do psicanalista. Ferenczi, foi um psicanalista, autêntico, audacioso e acima de tudo com uma capacidade de empatia, imprescindível para analista como função e lugar na clínica contemporânea. Ferenczi, foi um analista, sensível a subjetividade não só de sua época, mas, do contemporâneo também, mesmo sem ter ideia de suas contribuições e implicações que iriam causar em pleno século XXI. 


\section{REFERÊNCIAS}

AGUIAR, Tadeu Oliveira. As contribuições de Sandor Ferenczi, a formação do psicanalista. Fórum de Discussões - Práxis Psicanalítica. Evento em homenagem aos 148 anos de Sandor Ferenczi, O lugar de Sandor Ferenczi na história e na atualidade da psicanálise 2021. Disponível: O Lugar de Ferenczi na história e na atualidade da Psicanálise - YouTube Acesso em: 11 de julho de 2021.

COSTA, Rosane Albuquerque; AGUIAR, Tadeu Oliveira. Análise pessoal na formação do psicanalista em: Freud, Ferenczi e Lacan. Brazilian Journal of Health Review, 2021. Link disponível: Análise pessoal na formação do psicanalista em: Freud, Ferenczi e Lacan/ Personal analysis in psychonalist training in: Freud, Ferenczi e Lacan | Costa Brazilian Journal of Health Review (brazilianjournals.com) a

FERENCZI, S. (2011a) A elasticidade da técnica psicanalítica. In Obras Completas Psicanálise. Volume IV. São Paulo: Martins Fontes. (Original publicado em 1927-1928); FERENCZI, S. (1992) A técnica psicanalítica. In Obras Completas Psicanálise. Volume II. São Paulo: Martins Fontes. (Original publicado em 1919);

FERENCZI, S. (2011a) O problema do fim de análise. In Obras Completas Psicanálise. Volume IV. São Paulo: Martins Fontes. (Original publicado em 1927);

FERENCZI, S. (2011a) O processo da formação psicanalítica. In Obras Completas Psicanálise. Volume IV. São Paulo: Martins Fontes. (Original publicado em 1928);

FERENCZI, S. Psicanálise 1 / Introdução Michael Balint. Sandor Ferenczi; [tradução Álvaro Cabral; revisão técnica e tradução Cláudia Berliner]. $2^{\circ}$ ed. - São Paulo: Editora WMF Martins Fontes, 2011. - (Obras completas / Sandor Ferenczi; v. 1)

PINHEIRO, Teresa. (2016). Ferenczi. São Paulo: Casa do Psicólogo ROCHA, Ruth, 1931. Minidicionário/ Ruth Rocha; ilustrações Maria Luiza Ferguson - São Paulo; Scipione, 1996.

KUPERMANN, Daniel. Por que Ferenczi? Daniel Kupermann; coordenação Daniel Kupermann. - 1. Ed. - São Paulo: Zagodoni, 2019. 176 p. (Coleção Grandes Psicanalistas; 7. 